\title{
PADRE ANTÔNIO RIBEIRO PINTO NA RELIGIOSIDADE POPULAR POR MEIO DA LITERATURA DE CORDEL
}

\author{
PRIEST ANTÔNIO RIBEIRO PINTO IN POPULAR RELIGIOSITY THROUGH THE \\ CORDEL LITERATURE
}

Neffertite Marques da Costa ${ }^{1}$

\begin{abstract}
Resumo: Partindo do ciclo de folhetos sobre o Padre Antônio Ribeiro Pinto, publicado por Rodolfo Coelho Cavalcante, um dos maiores poetas da literatura de cordel, o artigo, utilizando o acervo digital da Fundação Casa de Rui Barbosa como fonte de pesquisa, propõe uma análise da construção mítica da figura do Padre Antônio na religiosidade popular. Para tal, passará pela biografia do sacerdote, por alguns dos milagres atribuídos a ele e pela religiosidade da cidade que ficou conhecida a partir de sua atuação, atraindo inúmeras pessoas da região Nordeste do Brasil em busca de milagres, o que foi registrado nos folhetos da Literatura de cordel por Rodolfo Coelho Cavalcante.
\end{abstract}

Palavras-chave: Padre Antônio Ribeiro Pinto; Rodolfo Coelho Cavalcante; literatura de cordel; religiosidade popular.

Abstract: From the cycle of brochures on Priest Antônio Ribeiro Pinto published by Rodolfo Coelho Cavalcante, one of the greatest poets of Cordel Literature, the article, using the digital collection House of Rui Barbosa Foundation as a research source, proposes an analysis of the mythical construction of the figure of Priest Antonio in popular religiosity. For that, it will go through the biography of the priest, some of the miracles attributed to him and the religiosity of the city that became known from his performance, attracting many people from the Northeast region of Brazil looking for miracles which was recorded Cordel Literature by Rodolfo Coelho Cavalcante.

Keywords: Priest Antônio Ribeiro Pinto; Rodolfo Coelho Cavalcante; Cordel Literature; popular religiosity.

\section{1) Introdução}

Os temas religiosos são predominantes na literatura de cordel brasileira. Os folhetos impressos serviram, inclusive, como fonte de transmissão de crenças religiosas, com a

\footnotetext{
${ }^{1}$ Mestranda em Ciência da Religião (PUC-SP), especialista em Ciências da Religião (PUC-SP), bolsista CAPES. Contato: profa.neffertite@gmail.com
} 
publicação de histórias bíblicas, vida de santos e milagres, perpetuando-se na memória popular pela facilidade mnemônica da métrica dos poemas. Em um país onde a maioria da população não era alfabetizada e os católicos não tinham acesso a Bíblia, o livro sagrado do Cristianismo, a literatura de cordel cumpriu uma importante função religiosa.

Rodolfo Coelho Cavalcante, além de uma biografia interessante e uma vasta produção bibliográfica, transitou por diferentes expressões religiosas - Catolicismo, Protestantismo, Pentecostalismo, Testemunha de Jeová, Espiritismo até optar por não ter uma religião -, representando, em algum sentido, a própria religiosidade popular brasileira, a qual circulou por diferentes expressões religiosas, conforme a necessidade, absorvendo alguns de seus elementos e os misturando ao universo cristão católico.

Essa expressão da religiosidade popular provocou o fenômeno do Padre Antônio Ribeiro Pinto, na Zona da Mata mineira, nas décadas de 1940 a 1960, com multidões, sobretudo oriundas do Nordeste brasileiro, com algum tipo de deficiência, em sua busca, o que permanece, com outro sentido, até os dias atuais, mesmo após a sua morte. Inúmeras curas foram atribuídas à benção do sacerdote, o que ele conferia à ação de Nossa Senhora das Graças, ensinando a crença na Imaculada Conceição, distribuindo a Medalha Milagrosa e atuando na construção de um santuário, em Urucânia, dedicado ao orago.

O presente artigo propõe a análise desse fenômeno religioso em que há características muito interessantes para o estudo das religiões, como o culto a Maria, a contraposição da religiosidade popular à teologia oficial católica e vice-versa, tendo por base o ciclo de folhetos de Rodolfo Coelho Cavalcante sobre o Padre Antônio Ribeiro Pinto, como fonte para a visão do povo a respeito do mesmo e a construção do mito em torno do sacerdote, já que, independente da própria confissão religiosa, ou mesmo na falta dela, o poeta da Literatura de cordel escrevia para ganhar dinheiro, ou seja, aquilo que agradava ao seu leitor.

$\mathrm{O}$ ciclo de folhetos em questão é formado pelos seguintes títulos: $A$ vida do Padre Antônio (O milagroso de Urucânia), de 1947; Os milagres do Padre Antônio, de 1947; O sermão do Padre Antônio, de 1948; e Nossa Senhora das Graças, sem data de publicação. $O$ sermão do Padre Antônio, indicado nos próprios folhetos de Rodolfo Coelho Cavalcante como o terceiro da série, o que confirma o levantamento de Eno Teodoro Wanke, um de seus biógrafos, não está disponível no acervo digital da Fundação Casa de Rui Barbosa, utilizado nesta pesquisa, mesmo possuindo um total de 507 folhetos do poeta. 


\section{2) Padre Antônio Ribeiro Pinto: sua vida e seu tempo}

A partir da metade do século XIX, o Brasil passou por mudanças que levaram ao fim da monarquia no país. Entre os diversos fatores que influenciaram, em maior ou menor grau, para a Proclamação da República, será considerado, para a análise proposta por este trabalho, o processo legal que levou à Abolição da Escravatura, com a Lei Eusébio de Queirós, de 1850, que proibia o tráfico de escravos para o Brasil; a Lei do Ventre Livre, de 1871, que conferia a liberdade às crianças nascidas de mães escravizadas; e a Lei dos Sexagenários, que garantia a liberdade para os escravos com mais de 60 anos.

Sabe-se que a Lei do Ventre Livre e a Lei dos Sexagenários tiveram poucos efeitos práticos e que, a anterior proibição do tráfico interatlântico, apenas incentivou o tráfico interno para as regiões cafeeiras do Rio de Janeiro e de São Paulo, já que o café era o principal produto de exportação no Império. Assim, como destaca Fausto, Minas Gerais, na passagem do Império para a República, ainda mantinha características existentes no período colonial, a saber: uma sociedade de relações escravistas com uma economia voltada ao mercado interno.

O território mineiro se dividia em várias regiões muito diversas e fracamente
integradas por causa das deficientes vias de comunicação. A Zona da Mata, onde se
localizavam cidades como Juiz de Fora, Leopoldina, Mar de Espanha, produzia café
e estava fortemente ligada fortemente ao Rio de Janeiro. O Vale do São Francisco
era uma zona de criação de gado que tinha relações mais estreitas com a Bahia e
Pernambuco do que com o resto da província. O Sul, onde se localizavam Pouso
Alegre, Passos, Itajubá, vinculava-se a São Paulo e à capital do Império. Apesar do
crescimento da produção cafeeira, exportada pelo Rio de Janeiro, Minas não se
vinculava predominantemente ao mercado externo. A base de sua economia
consistia na criação de animais e no cultivo de alimentos. [...] Até a Abolição, Minas
Gerais foi a província com a maior população do país e o maior número de escravos,
embora proporcionalmente a província do Rio de Janeiro a superasse em número de
cativos (FAUSTO, 2013, p. 205).

Foi nesse contexto histórico e nessa região que nasceu, em 2 de abril de 1879, Antônio Ribeiro Pinto, em Rio Piracicaba, localidade próxima à futura capital Belo Horizonte, a qual, no período, ainda era o arraial de Curral del Rei, distante do ideal positivista republicano responsável por transformá-la em uma das primeiras cidades planejadas do país e, por consequência, pela exclusão de sua população original, que não se enquadrava nos padrões de referência europeia das elites brasileiras.

Antônio Ribeiro Pinto era filho de uma escrava, nascendo livre em função da Lei de 1871. Foi criado com a ajuda dos tios, que o levaram, aos seis anos de idade, juntamente com a mãe, para Abre Campo, na Zona da Mata, onde ele estudou. Historicamente, a população da 
cidade foi formada pela atração da economia cafeeira, existente em função da proximidade com os Estados do Rio de Janeiro e do Espírito Santo. Não foi encontrado referências sobre a forma como a sua mãe pode mudar para a localidade: compra da alforria, fuga ou venda para algum proprietário de Abre Campo.

Permaneceu nesta região durante toda a sua vida. Aos vinte e um anos, o jovem Antônio se mudou para Alvinópolis, a fim de ingressar no seminário, onde se ordenou, em 9 de abril de 1912, voltando a Abre Campo para celebrar a sua primeira missa como padre. Tornou-se vigário no município vizinho de Santo Antônio do Grama, onde atuou por vinte e seis anos, até se mudar para Urucânia, em 11 de fevereiro de 1947, então já com 67 anos de idade, a pedido do Padre José Henrique de Souza Carvalho, onde faleceu em 22 de julho de 1963.

Em 2009, um grupo de devotos iniciou a mobilização em prol da abertura do Processo de Beatificação do Padre Antônio Ribeiro Pinto, reunindo, juntamente com a coleta de assinaturas e as provas de seus milagres, um material sobre a vida e a obra do sacerdote. Acerca do processo, formalmente iniciado, com a entrega das assinaturas ao Arcebispo de Mariana, em uma missa celebrada em Urucânia, em 24 de novembro de 2010, não há informações.

\section{3) A religiosidade em Urucânia}

O Padre Antônio Ribeiro Pinto atuou por dezesseis anos em Urucânia, município localizado no Estado de Minas Gerais. O nome da cidade vem de urucu ou urucum, que em tupi-guarani significa vermelho, em razão do fruto do urucuzeiro, fartamente encontrado na região, de onde se extrai o corante utilizado na culinária brasileira. Na década de 1920, teve início o cultivo extensivo de cana-de-açúcar, assim como a instalação de usinas açucareiras, fornecendo a segunda parte do nome da cidade, "cana".

A formação oficial do povoado data de 1873, mesma década em que nasceu o Padre Antônio, sendo, em 1889, elevado à categoria de vila e, em 1938, passou a fazer parte do município de Ponte Nova. Em 30 de dezembro de 1962, Urucânia se desmembrou de Ponte Nova e passou a ser um município independente. Mas a região, localizada na Zona da Mata mineira, distante 230 quilômetros da capital, já era ocupada desde o início do século XIX.

A forte religiosidade acompanha toda a história de Urucânia. Em 1887, o povoado, inaugurado apenas catorze anos antes, foi reconhecido como uma freguesia, para o que havia a exigência de atendimento por um sacerdote, o que foi possível com a construção de uma capela e uma casa para abrigar o padre, após a doação de terras de Francisca Inácia da [revista Último Andar (ISSN 1980-8305), n. 32, dezembro de 2018] 
Incarnação, católica fervorosa, em torno de 1869. A capela foi dedicada a Nossa Senhora do Bom Sucesso do Urucu, dando origem à igreja matriz da cidade, construída em 1887.

\begin{abstract}
Inicialmente a virgem do Bom Sucesso era invocada para proporcionar aos seus devotos uma "boa morte", pois o maior sucesso desejado por todos era uma "hora feliz" seguida da salvação eterna. Com o objetivo de implorar o seu auxilio nos últimos momentos, foi iniciada em Portugal, no século XVI, uma irmandade cuja protetora era Nossa Senhora do Bom Sucesso dos Agonizantes. No inicio do século seguinte, por volta de 1637, veio para o Rio de Janeiro o padre Miguel Costa, do hábito de São Pedro, muito devoto da Senhora do Bom Sucesso. Não querendo separar-se de sua Padroeira, o piedoso sacerdote trouxe consigo uma imagem desta Santa e colocou-a na capela da Santa Casa de Misericórdia. [...] No final do século XVII havia em Pindamonhangaba, no atual Estado de S. Paulo, uma pequena matriz dedicada à Senhora do Bom Sucesso. Entre seus inúmeros devotos estava o padre João de Faria Fialho, também do hábito de São Pedro, que procurou reedificar e enriquecer a casa da Mãe Santíssima. Alguns anos mais tarde esse mesmo padre Faria tomou parte em uma das primeiras bandeiras de desbravamento nos sertões de Cataguás e descobriu ricas jazidas de ouro do sopé do Itacolomi, no local onde hoje se encontra o bairro de Ouro Preto, que tomou o seu nome. [...] Devido ao estupendo êxito da "bandeira" do padre Faria, a Senhora do Bom Sucesso passou a ser invocada também como Protetora dos bens terrenos, não perdendo entretanto o seu antigo caráter protetor (MEGALE, 1986, p. 73 e 74).
\end{abstract}

Após chegar à região das minas, a devoção a Nossa Senhora do Bom Sucesso, então popular entre aqueles que procuravam ouro, se espalhou na direção leste, dando origem ao município de Caeté, e Nordeste, no município de Minas Novas, com grandes igrejas dedicadas ao orago. A partir da referida capela, foi construída a igreja matriz de Urucânia, mas, hoje, é o Santuário de Nossa Senhora das Graças, um sonho do Padre Antônio Ribeiro Pinto, que se concretizou após a sua morte, que atrai para o município um grande número de fiéis católicos, o que já ocorria no final da década de 1940, chamando a atenção dos jornais da época e dos poetas dos folhetos da literatura de cordel.

Chamava a atenção de todo o Brasil, especialmente do Nordeste, onde se fretavam
caminhões e mais caminhões de romeiros em busca da cura para seus males. [...]
"Os milagres do Padre Antonio" de Rodolfo [Coelho Cavalcante] teve sua primeira
edição de cinco mil exemplares esgotada em poucos dias. Em três meses, já havia
alcançado mais de sessenta mil unidades vendidas. [...] Saindo de Salvador com seus
folhetos, Rodolfo fez uma excursão pelo interior da Bahia, perambulando entre
Jacobina, Senhor do Bonfim e Juazeiro da Bahia, com sua coleção de folhetos sobre
o Padre Antônio. Até dois mil folhetos chegava a vender num dia, pois muitos
compravam de cinco a dez exemplares de uma vez (WANKE, 1983, p. 150). O Padre Antônio Ribeiro Pinto era devoto de Nossa Senhora das Graças e fiel ao dogma da Imaculada Conceição, tratando logo de propagar o culto mariano e se empenhando na construção do santuário. Ainda hoje as Medalhas Milagrosas são distribuídas no santuário de Nossa Senhora das Graças, que recebe, segundo informação da Prefeitura Municipal, disponível na rede mundial de computadores, cerca de 40 mil visitantes por ano, inclusive de outros países, destacando-se mexicanos, canadenses, franceses e ingleses. Estes, além do 
santuário, encontram no local o Museu Padre Antônio Ribeiro Pinto e a Casa dos Milagres, onde tem acesso aos objetos pessoais e correspondências do sacerdote, assim como os exvotos deixados pelos romeiros.

Dessa forma, a religiosidade permanece como um forte dado cultural do município de Urucânia, onde se celebra a Festa de Nossa Senhora do Bom Sucesso, em 11 de outubro; a Festa de Nossa Senhora das Graças, em 27 de novembro; e a Páscoa com grandes encenações. Em homenagem ao Padre Antônio Ribeiro Pinto, a data de 22 de julho foi escolhida como o Dia da Cidade, comemorado com um feriado municipal.

\section{4) A literatura de cordel e o poeta Rodolfo Coelho Cavalcante}

A literatura de cordel ou literatura de folhetos, nomenclatura variável de acordo com a interpretação do pesquisador, embora tenha ficado conhecida popularmente pela primeira designação, é um tipo de literatura recorrente na região Nordeste do Brasil, difundida para o restante do país, que teve início com a publicação dos poetas Leandro Gomes de Barros (1865-1918), que começou a publicar seus poemas em folhetos em 1893; João Martins de Ataíde (1880-1959), que iniciou as suas publicações em 1902; e Francisco das Chagas Batista (1882-1930), que publicou o primeiro folheto em 1908.

Com um formato gráfico específico, adotado a fim de reduzir os custos de produção e, portanto, de comercialização, retomaram uma tradição existente na Europa medieval de imprimir narrativas, tanto em prosa quanto em verso, em folhetos, os quais, na Península Ibérica, eram vendidos pendurados em um barbante chamado de cordel, o que deu origem a designação de Literatura de cordel pelos primeiros estudiosos dessa produção literária. Também empregavam uma métrica que caracterizava a poesia: versos heptassílabos em sextilhas (estrofes de seis versos), septilhas (estrofes de sete versos) ou décimas (estrofes de dez versos).

\footnotetext{
Documentário de costumes e de mitos do mundo rural brasileiro ou recriação escrita de uma tradição oral herdada da Europa, o folheto deixa entrever, sob uma denominação múltipla, as ambigüidades de sua identidade. $\mathrm{O}$ termo folheto de feira é empregado tradicionalmente para designar esse pequeno livro, cujo número de páginas varia de 8 a 48 (podendo chegar, excepcionalmente, até 64 páginas), com um formato médio de 11 x $64 \mathrm{~cm}$., imposto pelo modo de distribuição (SANTOS, 2006 , p. 60,61$)$.
}

A ambiguidade indicada por Santos refere-se à associação imediata que pode ser feita com o mesmo tipo de literatura produzida em Portugal, quando os folhetos portugueses traziam histórias tradicionais em prosa e, desde o início, os folhetos produzidos no Brasil [revista Último Andar (ISSN 1980-8305), n. 32, dezembro de 2018] 
registraram poesias, não sendo, assim, uma reprodução ou mera recriação da literatura de cordel portuguesa. Uma característica fundamental da literatura de cordel brasileira é a presença da religiosidade, elemento característico da região Nordeste, com os costumes e mitos do mundo rural, como apontou a pesquisadora em sua definição.

Segundo CURRAN (1987), as temáticas recorrentes neste tipo de literatura são os poemas católicos tradicionais, com histórias de Jesus e de Maria; os poemas sobre o "fim de eras", de teor apocalíptico, com a predominância de mensagens marianas; os poemas sobre o messianismo popular, com narrativas sobre Antônio Conselheiro, Padre Cícero e Frei Damião; os poemas de discussão entre católicos e protestantes, que marcam o início da produção de folhetos, assim como a chegada dos missionários protestantes no Nordeste; e os poemas sobre o Espiritismo, aparecendo nos versos o Candomblé, a Umbanda e as interpretações de Allan Kardec.

Ao lado de Leandro Gomes de Barros, o poeta com o maior destaque na Literatura de cordel brasileira foi Rodolfo Coelho Cavalcante, que nasceu em 12 de março de 1919, em Rio Largo, hoje município de Gustavo Paiva, no Estado de Alagoas. Filho de Artur de Holanda Cavalcante e Maria Coelho Cavalcante teve uma infância difícil, sobretudo pelo problema de alcoolismo do pai, chegando a fugir várias vezes de casa, razão pela qual começou a trabalhar cedo. Entre 1934 e 1942, trabalhou no circo, onde adquiriu experiência como autor, ator, palhaço, mágico e administrador.

Iniciou a publicação de folhetos em Teresina, no Estado do Piauí, se estabelecendo, em 1945, na Bahia, onde exerceu liderança junto aos demais poetas, organizando congressos de trovadores e violeiros. Rodolfo Coelho Cavalcante possui uma vasta produção de poemas, com mais de mil e setecentos folhetos impressos, conforme CURRAN (1987), um dos seus biógrafos e pesquisador desse tipo de literatura. Faleceu em 1987, em frente a sua casa, em Salvador, vítima de um atropelamento.

\section{5) Padre Antônio, o Milagroso de Urucânia}

A biografia do sacerdote foi objeto do folheto A vida do Padre Antonio (O Milagroso de Urucania), de Rodolfo Coelho Cavalcante, disponibilizado no acervo digital da Fundação Casa de Rui Barbosa, então em sua segunda edição, publicada em novembro de 1947. O poema, impresso em oito páginas, foi escrito em septilhas, com uma rima ABCBDDB, como a maioria de seus folhetos. O Padre Antônio Ribeiro Pinto é nomeado como o Milagroso de 
Urucânia, quando, em outro folheto, Maria, na devoção à Nossa Senhora das Graças, é quem foi denominada como a Milagrosa de Urucânia.

O folheto Nossa Senhora das Graças, sem informação da data de publicação, tem uma estrutura bastante incomum, sendo parte em septilhas, com sete versos em cada estrofe, com uma rima $\mathrm{ABCBDDB}$, a forma que predomina na obra de Rodolfo Coelho Cavalcante; e parte em décimas, com dez versos em cada estrofe, mantendo irregularidade nas rimas, por vezes ABBAACCDDC e em outras AAAABCCCCB. É caracterizado como um poema de exaltação, trazendo versos que enaltecem a figura de Maria, com diversos títulos atribuídos a ela pela teologia católica.

Embora o folheto tenha o título de Nossa Senhora das Graças e traga impressa na capa uma imagem da referida devoção, com Maria, em pé sob o globo terrestre, com raios de luz saindo de suas mãos, a representação mais presente de Maria no folheto é a da Imaculada Conceição, já que ambos os títulos estão diretamente ligados e eram propagados como devoção pelo Padre Antônio Ribeiro Pinto. Na última página do folheto foi impressa uma oração que o poeta afirma ser ensinada pelo sacerdote aos fiéis, a saber:

\footnotetext{
Santíssima Virgem eu creio e confesso vossa Santa e Imaculada Conceição, pura e sem mancha. Ó Puríssima Virgem Maria, por vossa Conceição Imaculada e Gloriosa prerrogativa de mãe de Deus alcançai-me de vosso amado Filho a humildade, a caridade, a obediência, a castidade, a santa pureza de coração, do corpo e do espírito, a perseverança na prática do bem, uma boa vida e uma santa morte. Amém.
}

A oração, rezada e ensinada pelo Padre Antônio, não se dirigia especificamente à invocação de Nossa Senhora das Graças, denominando Maria como "Santíssima Virgem" e "Puríssima Virgem Maria", para a qual pedia as virtudes cristãs da humildade, da obediência, da caridade, da pureza do corpo e da alma, além de uma boa vida e uma santa morte, em nome da Conceição Imaculada de Maria e de seus méritos como Mãe de Deus, ambos decretados como dogmas pela Igreja Católica Romana; este, em 431, no Concílio de Éfeso, e aquele, em 1854, pelo Papa Pio IX.

Essa é a oração final da novena de Nossa Senhora das Graças, composta pelas fórmulas católicas do ato de contrição; a Ave-Maria, acompanhada da jaculatória "Ó Maria concebida sem pecado, rogai por nós que recorremos a vós"; a meditação do dia; e a oração final. A jaculatória foi cunhada na Medalha Milagrosa, propagada a partir da dita aparição de Maria à Catarina Labouré, em Paris, na França, em 27 de novembro de 1830, em que foi vista na forma que ficou consagrada a iconografia da devoção, recebendo o título de Nossa Senhora das Graças em função dos raios luminosos significarem as graças que Maria teria afirmado querer distribuir à humanidade. 
Em 1830, Nossa Senhora apareceu em Paris a Santa Catarina Labouré e ordenou-lhe que fosse cunhada uma medalha sua, com a invocação: "Ó Maria concebida sem pecado, rogai a nós, que recorremos a Vós”. Aprovada pelo Arcebispo de Paris, Mons. de Quélen, essa medalha imediatamente teve enorme difusão e se tornou mundialmente célebre como a Medalha Milagrosa. Isso contribuiu poderosamente para a criação do contexto no qual se deu a proclamação dogmática. Com efeito, Pio IX, pela Carta Apostólica Ineffabilis Deus, de 8 de dezembro de 1854, solenemente proclamou como Dogma de Fé a Imaculada Conceição da Santíssima Virgem (SANTOS, 1996, p. 56).

O evento confirmou para o universo católico a crença na Imaculada Conceição de Maria. Em $1^{\circ}$ de novembro de 1950, ainda seria proclamado o dogma da Assunção de Maria, por meio da Constituição Dogmática Munificentissimus Deus, pelo Papa Pio XII. O curioso é que os conceitos destes dogmas marianos já existiam no Brasil desde o período colonial, por meio das devoções a Nossa Senhora da Conceição e Nossa Senhora da Glória, trazidas pelos portugueses, estando o culto mariano intimamente ligado à história política de Portugal.

Nos primeiros séculos do Cristianismo, desenvolveu-se o paralelismo simbólico
entre Maria e Eva, compreendidas como a virgem desobediente (Eva) que leva a
humanidade ao mal e a virgem obediente (Maria) que abre caminho para o bem.
Nasce também a devoção mariana. [...] No século VIII, surge no Oriente a Festa da
Concepção de Maria, que era celebrada como devoção no dia 9 de dezembro. No
século seguinte, é introduzida na Itália bizantina. E na virada do primeiro milênio
começa a se difundir no Ocidente, sobretudo na Inglaterra. Dali se espalha para a
França, a Espanha e a Itália de tradição ocidental (MURAD, 2012, p. 163).

Imprimindo novamente a oração final da novena na última página do folheto $A$ vida do Padre Antonio (O Milagroso de Urucania), Rodolfo Coelho Cavalcante tentou aproximar a biografia do sacerdote às virtudes indicadas na prece: nasceu pobre, era um piedoso cristão e fervoroso desde a infância, aos onze anos já dizia que seria um padre, repartia o lanche na escola, ensinava o catecismo, cresceu com ardente pureza e amor pela pobreza, era um filho obediente, não mentia nem jurava em nome de Deus, continuou socorrendo os famintos e consolando os aflitos, tornou-se um pastor amigo do povo, sem vaidade ou egoísmo, aconselhava que tomassem Nossa Senhora das Graças como espelho.

\section{A vida de Padre Antonio \\ Padre Antonio sempre \\ Mensageiro da verdade \\ Interpreta os Evangelhos \\ Com mais pura Santidade \\ Não ataca o inimigo \\ Antes se faz um amigo \\ Praticando a caridade \\ O sorrir do Padre Antonio \\ Nos conforta o coração \\ Os seus conselhos leitores \\ É o mais belo sermão \\ A sua fé que é sem par}


Tem o poder de curar

A todo e qualquer cristão

Rodolfo Coelho Cavalcante colocou na boca de um velho sapateiro, aquele que afirmam ser o primeiro milagre do Padre Antônio, ainda em 1912, quando teria pedido a Nossa Senhora das Graças que tirasse o vício da mãe, após encontra-la caída e embriagada na rua, transferindo-o para ele, ao que ela parou de beber e o recém-sacerdote enfrentou o alcoolismo. Contudo, o mesmo poeta, diz para os leitores creem ser isso "lenda e fantasia", pois o próprio Padre Antônio teria afirmado que nem ele, nem a mãe ou o pai nunca beberam.

No folheto Os milagres de Padre Antonio, disponível no acervo digital da Fundação Casa de Rui Barbosa, este em sua sétima edição, publicada em dezembro de 1947, também em septilhas, com uma rima $\mathrm{ABCBDDB}$, impresso em oito páginas, fornece uma ideia dos milagres atribuídos ao sacerdote e a forma pela qual o padre os interpretava como uma das graças de Maria. No material, há uma clara preferência de Rodolfo Coelho Cavalcante por histórias que causem assombro em seus leitores, ao deixar claro com exemplos que não se deveria zombar do Padre Antônio Ribeiro Pinto ou de Nossa Senhora das Graças.

\section{Os milagres de Padre Antonio}

$$
\begin{aligned}
& \text { Chegando ao Padre Antonio } \\
& \text { A sua filha mostrou } \\
& \text { O Padre disse: minha filha } \\
& \text { A tua fé te salvou } \\
& \text { Na mesma a hora a mocinha } \\
& \text { Disse: Tou "vendo" mãesinha } \\
& \text { De tanto jubilo chorou } \\
& \text { [...] } \\
& \text { Disse a ela o padre Antonio } \\
& \text { Não fui eu que te curei } \\
& \text { Nossa Senhora das Graças } \\
& \text { Me disse tudo já sei } \\
& \text { Vae e dises teu marido } \\
& \text { Todo este acontecido } \\
& \text { Que dê glória ao grande Rei }
\end{aligned}
$$

Em agradecimento, a mãe teria oferecido dinheiro como esmola, ao que teria sido repreendida pelo sacerdote, acabando por deixar aos pés da imagem de Maria. Já em casa, viu a zombaria do marido, que via o Padre Antônio como um aproveitador. No dia seguinte, encontraram a filha morta com o determinado valor em mãos, falecendo, no mesmo dia, a mãe, o que fez o marido enlouquecer. Nos versos, o poeta afirmou que o caso foi noticiado em um jornal baiano, mencionando outro fato ocorrido em Rio Casca, município vizinho da futura Urucânia, em que um homem, alcoólatra, morreu após colocar a Medalha Milagrosa, 
que havia recebido do próprio Padre Antônio, no copo em que bebia, zombando do sacerdote, provavelmente em um período em que este passou na localidade.

Rodolfo Coelho Cavalcante também fez menção a cura do braço paralisado, por onze anos de Maria Simões que ouvia o Padre Antônio Ribeiro Pinto pelo rádio, assim como a cura de ex-combatentes das Forças Expedicionárias Brasileiras na Segunda Guerra Mundial. Milagres que teriam sido confirmados, segundo o poeta, pelo jornalista David Nasser, em reportagem para a revista semanal $O$ Cruzeiro. No final do folheto, novamente imprimiu a oração final da novena de Nossa Senhora das Graças.

\section{6) A religiosidade popular em contraste com a teologia oficial}

O Padre Antônio frequentou o seminário, para a formação sacerdotal, em um período de transformação do Catolicismo no Brasil, em função do anúncio da separação entre a Igreja e o Estado, em 1890, pelo Governo republicano, o que fez com que a hierarquia católica, buscando confirmar a sua influência junto à sociedade, se reaproximasse de Roma e promovesse uma reforma interna, pois, no período do Padroado, a educação dos padres foi pouco ortodoxa e a disciplina clerical bastante relaxada, contando, para tal, com os missionários redentoristas, de mentalidade tridentina, que chegaram, em 1894, para as missões populares e para o cuidado dos santuários, processo conhecido como "romanização".

Dessa forma, foi principalmente nos santuários que os conflitos entre esse catolicismo agora oficial, renovado, e o catolicismo devocional, popular, barroco, também chamado de tradicional, já que era praticado dessa forma desde o inicio da colonização, entraram em cena, opondo os missionários e os romeiros de costumes considerados nativos. A religiosidade manifestada por séculos passou a não ser tão bem vista - Folia de Reis, Festa do Divino, as comemorações juninas, os pastoris e o bumba meu boi dos autos de Natal -, sendo, então, aceitas apenas como expressões folclóricas.

São suas marcas que se veem nesses maracatus que, tal como o cortejo processional que o desfile das escolas de samba recria, se deslocam agora, inteiramente "profanos" - todavia, será mesmo assim? -, para o Carnaval, bem como nessas congadas e moçambiques que ainda celebram são Benedito, a Senhora do Rosário e a Aparecida, nessas devoções de maio, mês de Maria, quando comunidades negras ainda coroam seus reis do Congo, nessas ladainhas em latim que os pretos velhos rezadores ainda são capazes de recitar, nessas procissões e romarias a santuários que se espalham do Bom Jesus da Lapa e dos Perdões aos de Pirapora, e que continuarão, em pleno século XX, ao Juazeiro do Padre Cícero. É para esse catolicismo do devocionário popular, no entanto, que a Igreja, sob o império da romanização, volta decididamente as costas. Considerado forma de exteriorização "vazia" da fé, expressão da ignorância do povo ou obra de perversão e maldade, a ele o clero livra um combate sem tréguas ao longo das décadas de 30 e 40 (MONTES, 1998, p. 111 e 112).

[revista Último Andar (ISSN 1980-8305), n. 32, dezembro de 2018] 
No período mais intenso deste combate, o Padre Antônio já atuava como sacerdote. Chegando a Urucânia, no final da década de 1940, passou a atrair milhares de pessoas em busca de cura física e psíquica - deficientes físicos, visuais, auditivos e intelectuais -, que, uma vez obtidas no meio da massa, provocava conversões, sendo responsável por aproximálas da liturgia oficial, com inúmeras confissões e comunhões, algo que muitos não tinham acesso em seus locais de origem, já que a proibição das ordens religiosas receberem noviços, ocorrida no período do Padroado, diminuiu ou mesmo cessou a oferta de padres nos sertões.

Enquanto isso, os redentoristas, concentrados em Aparecida, embora também tivessem fundado a Missão Redentorista de Goiás, trabalhavam, paralelo à hierarquia católica, não só para fortalecer a devoção a Nossa Senhora Aparecida, mas para torná-la a Padroeira do Brasil, o que teria a função de concentrar os peregrinos no Centro-Sul do país e retirar a força de antigos santuários das regiões Norte e Nordeste, que, há muito tempo, faziam parte da peregrinação popular.

\begin{abstract}
A falha estrutural na devoção a N. Sra. Aparecida é provavelmente responsável pela estranha instabilidade do seu calendário. Foi festejada a 8 de dezembro desde o século XVIII, devido a seu nome "Conceição", o episcopado, contudo, decidiu criar um dia especial para "Aparecida", e a primeira escolha (de 1885) foi para o quinto domingo depois da páscoa, que caia no mês de maio, proclamado mês de Maria pelo Vaticano (1878). Mais tarde (1904) a data foi oficialmente mudada para o primeiro domingo de maio. Diversos programas da Igreja, contudo, pressionavam para fixar 8 de setembro ("Natividade"), talvez pela proximidade com a festa-mor da "nação". Finalmente, em 1939, o 7 de setembro foi solenemente declarado o dia de Aparecida, mas os romeiros não corresponderam e as festividades foram esvaziadas de presença popular. Em 1955, a CNBB reconheceu o fracasso daquela data (com efeito, um curto-circuito ritual) e mudou o dia de aparecida para 12 de outubro, que "vingou". Ainda assim, quando o 12 de outubro tornou-se feriado nacional em 1980, a maioria das pessoas ficou desorientada, por desconhecer o motivo (FERNANDES, 1989, p. 23).
\end{abstract}

Nesse sentido, é possível entender o Padre Antônio Ribeiro Pinto como uma figura intermediária entre a religiosidade popular, em busca de milagres instantâneos, de taumaturgos e de místicos nos pontos mais distintos do país, e a teologia oficial, ao estimular e promover o acesso aos sacramentos católicos do batismo, da confissão e da Eucaristia, a devoção mariana e o dogma da Imaculada Conceição, o uso de sacramentais aceitos pela Igreja Romana, como é o caso da Medalha Milagrosa, com um discurso capaz de atingir os fiéis mais afastados da Igreja sem romper com ela ou os seus ensinamentos.

\title{
7) Considerações Finais
}

Relembrando a oração final da novena de Nossa Senhora das Graças, impressa nos folhetos apontados, o pedido de uma santa morte vai ao encontro do inicio da devoção a 
Nossa Senhora do Bom Sucesso, no entanto, a invocação já chegou à região de Urucânia tendo outro caráter, ou seja, o de sucesso financeiro. O que leva a uma questão: os católicos, hoje, fazem as suas orações pedindo uma santa morte, como também indicam as orações AveMaria e Salve-Rainha, e o faziam ao longo do século XX?

Atualmente, em Urucânia, os fiéis recorrem ao santuário por causa da mediação de Nossa Senhora das Graças ou o fazem ainda esperando um milagre do Padre Antônio, a quem realmente consideram santo? E no passado, o fizeram em algum momento pela mediação de Maria? Qual é o motivo que continua levando tantas pessoas aos santuários, que recebem essa denominação justamente por serem locais de grande peregrinação? Houve e há somente a busca da cura dos males físicos ou existiu e existe, por parte dos devotos, uma real intenção de viver conforme as virtudes cristãs, aquelas expostas na oração final da novena?

Está claro que o modus operandi dos sacerdotes e dos fiéis é muito diferente. Os devotos, que mantem práticas devocionais do medievo católico, tem uma relação pessoal com o seu santo de devoção, baseada em uma troca de favores, que escapa às orientações da liturgia oficial. Mesmo quando falam da mesma coisa, não é a mesma coisa. O povo entende cada "Nossa Senhora" como um personagem diferente e não como uma única figura religiosa invocada com nomes diversos.

O que é certo é que a religiosidade popular não necessita de explicações teológicas e dogmáticas para existir. Por um lado, é uma fé simples; por outro, é uma fé de verdade, justamente, por não precisar de muitas explicações para existir. Apesar da reforma religiosa, algumas manifestações dessa religiosidade foram "vitoriosas", ou, no mínimo, sobreviveram: a Folia de Reis e a Festa do Divino, por exemplo, ainda acontecem em diversas paróquias, com o apoio da hierarquia católica local, mesmo que se submetendo as suas exigências.

A forma como os ouvintes e leitores de Rodolfo Coelho Cavalcante consumiram o ciclo de folhetos do Padre Antônio Ribeiro Pinto demonstra como pareciam ávidos por saberem mais desses "santos", dos taumaturgos que curassem seus males físicos e psíquicos. Provavelmente, muitos deixaram de notar o dado mais interessante acerca do Padre Antônio: um sacerdote negro ou, no mínimo, mulato, já que não foi encontrada informação a respeito de seu pai, que conseguiu estudar e se ordenar naquele exato momento da história do Brasil, com erudição e conhecimento teológico para estar alinhado com os principais dogmas católicos, como o da Imaculada Conceição. 


\section{Referências bibliográficas}

Cordel - Fundação Casa de Rui Barbosa. http://docvirt.com/docreader.net/docreader.aspx?bib $=$ CordelFCRB\&pasta. Acesso em junho de 2018.

CURRAN, Mark J. A presença de Rodolfo Coelho Cavalcante na moderna literatura de cordel. Rio de Janeiro: Nova Fronteira; Fundação Casa de Rui Barbosa, 1987.

FAUSTO, Boris. História do Brasil. 14. ed. atual. e ampl. São Paulo: Editora da Universidade de São Paulo, 2013.

FERNANDES, Rubem César. Aparecida: Nossa Rainha, Senhora e Mãe, Saravá! In: Teologia e devoção mariana no Brasil. ed Caliman, Cleto (org.). São Paulo: Paulinas, 1989.

MEGALE, Nilza Botelho. Cento e doze invocações da Virgem Maria no Brasil: Históriaiconografia-folclore. Petrópolis: Vozes, 1986.

MONTES, Maria Lucia. As figuras do sagrado: entre o público e o privado. In: História da vida privada no Brasil. ed Schwarcz, Lilia Moritz (org.). Vol. 4. São Paulo: Companhia das Letras, 1998.

MURAD, Afonso Tadeu. Maria, toda de Deus e tão humana: Compêndio de mariologia. São Paulo: Paulinas, Santuário, 2012.

Padre Antônio Ribeiro Pinto. https://padreantonioribeiropinto.wordpress.com. Acesso em junho de 2018.

Prefeitura Municipal de Urucânia. www.urucania.mg.gov.br. Acesso em junho de 2018.

SANTOS, Armando Alexandre dos. O Brasil sob o manto da Imaculada. São Paulo: Artpress, 1996.

Santuário Urucânia. http://santuariourucania.com.br. Acesso em junho de 2018.

WANKE, Eno Teodoro. Vida e luta do trovador Rodolfo Coelho Cavalcante. Rio de Janeiro: Folha Carioca Editora Ltda., 1983. 